\title{
La adopción en Colombia: un proceso judicial, psicológico y emocional. Reflexión a partir de una experiencia personal ${ }^{*}$
}

\section{- Sara Alicia matarazzo Boriani}

Fui adoptada cuando era niña y desde que tengo memoria llevo impresa en mi mente la imagen de niños y niñas acostados en las calles de Bogotá, durmiendo en los andenes, sin comida, sin familia, sin derechos, sin futuro ni posibilidad de tener una vida digna. Nací en Bogotá y siento que fui una niña muy afortunada por haber encontrado mi familia maravillosa en Italia. No obstante, nunca olvidé mis orígenes y durante toda la vida tuve un gran deseo de hacer algo para cambiar la difícil situación social, política, jurídica y humana que afecta no solamente a los niños de Colombia y Latinoamérica, sino también -y desafortunadamentea muchísimos niños en tantos países del mundo.

Todo empezó en 1992, cuando mis padres y yo regresamos a Bogotá para adoptar a mi hermanita. Yo tenía casi 4 años cuando comencé a mostrar a mis papás inquietudes específicas sobre los niños que veía en esas condiciones. Mientras cruzábamos los barrios de la capital colombiana, empecé a preguntarles por qué estos niños estaban acostados en la calle, por qué ellos no podían jugar con

Fecha de recepción: 4 de abril de 20I6. Fecha de aceptación: 9 de octubre de 2016.

Para citar el artículo: S. A. Matarazzo Boriani, "La adopción en Colombia: un proceso judicial, psicológico y emocional. Reflexión a partir de una experiencia personal", Revista de Derecho Privado, Universidad Externado de Colombia, n. ${ }^{\circ}$ 31, julio-diciembre de 2016, 409-427. Dor: http://dx.doi.org/I0.1860 I/oI 234366.n31.I6

Este trabajo tiene el objetivo de analizar el proceso de adopción en Colombia, no solamente desde la perspectiva legal, sino considerando también los diferentes aspectos psicológicos y emocionales que implica esta figura jurídica cargada de sentimientos humanos.

** Especialista en Derecho de Familia de la Universidad Externado de Colombia, Bogotá, Colombia. Representante legal en Colombia de la ONG Bethany Christian Services International Inc. Contacto: saraliciangelica@hotmail.it 
otros niños, y qué hacían allí. Preguntaba a mis padres por qué estos niños no podían comer normalmente en lugar de "comer" gasolina de los carros. Preguntaba por qué tantos niños y niñas no podían dormir en una cama de verdad, en vez de dormir en cajas de cartón cerca de las estaciones de gasolina, y comencé a preguntarme a mí misma por qué estos niños no sonreían como lo pude hacer yo durante toda mi infancia.

\section{La adopción es un acto de amor puro}

- ¿Qué significa "domesticar"?

- Es algo demasiado olvidado -dijo el zorro-. Significa "crear lazos...".

- Crear lazos?

- Claro - dijo el zorro-. Todavía no eres para mí más que un niño parecido a otros cien mil niños. Y no te necesito. Y tú tampoco me necesitas. No soy para ti más que un zorro parecido a otros cien mil zorros. Pero, si me domesticas, tendremos necesidad uno del otro. Tú serás para mí único en el mundo. Yo seré para ti único en el mundo... [...] [S]i me domesticas, mi vida resultará como iluminada. Conoceré un ruido de pasos que será diferente de todos los demás. Los otros pasos me hacen volver bajo tierra. Los tuyos me llamarán fuera de la madriguera, como una música. Y además, ¡mira! ¿Ves, allá lejos, los campos de trigo? Yo no como pan. El trigo para mí es inútil. Los campos de trigo no me recuerdan nada. $Y$ jeso es triste! Pero tú tienes cabellos color de oro. Entonces jserá maravilloso cuando me hayas domesticado! El trigo, que es dorado, me hará recordarte. $Y$ me agradará el ruido del viento en el trigo...

El zorro se calló y miró largamente al principito:

- Por favor... ;domesticame! -dijo.

Antoine de Saint-Exupéry, El Principito $^{\mathrm{I}}$.

"Domesticar" significa crear lazos, es decir, vínculos que no necesariamente son fuertes por el simple hecho de que son lazos de sangre: hay vínculos aún más fuertes que, como expresa una dicción popular colombiana, "llaman más que la sangre”. A través de las palabras del Principito, esta mágica obra que enriqueció la infancia de muchos niños en todo el mundo, mis padres me explicaron qué significa ser una niña adoptada: que nuestros lazos son especiales y únicos en el mundo, porque adoptar significa "amar".

Según Henri y León Mazeaud, la adopción es definida como "un acto voluntario y libre que crea, afuera de los vínculos de la sangre, un vínculo de filiación entre dos personas" ${ }^{2}$. De hecho la adopción es un proceso judicial que crea un vínculo de amor.

I Reynal \& Hitchcock (EUA), I943, cap. 2 I.

2 Mazeaud, H. y L. et al., Lecciones de derecho civil, Parte i. ${ }^{a}$, vol. iII, Buenos Aires, Ediciones Jurídicas Europa-América, I976, 553. 


\section{De adoptio a adopción, un breve excursus histórico}

La figura jurídica de la adopción tiene orígenes muy antiguos y ha ido cambiando y desarrollando funciones y efectos diferentes con el pasar de la historia. Durante el Imperio Romano existían dos técnicas jurídicas que podemos familiarmente llamar los "tatarabuelos de la adopción", aunque sus efectos eran completamente distintos de los que tiene la adopción actualmente. In primis existía el instituto de la mancipatio, por medio del cual se realizaban ventas de "res", es decir objetos y personas consideradas objetos, que se podían "mancipar", esto es, separar de la propiedad del dominus 3 . Este procedimiento era muy sencillo: "banc ego rem ex iure quiritium meum ese aio [afirmo que esta cosa me pertenece según el derecho romano]"; si ante tal afirmación quien transmitía no se oponía, significaba que estaba cediendo (in iure cessio) ante la pretensión del adquirente y el magistrado adjudicaba la propiedad de la cosa a quien la reivindicaba como suya ${ }^{4}$.

En la familia de la antigua Roma el jefe absoluto -el pater familias - tenía poder ilimitado sobre todos los miembros de aquella y a través de la mancipatio podía, literalmente, vender a sus hijos: tres ventas si era un varón púber o una sola venta si se trataba de una hija o un niño menor de edad.

En segundo lugar, existía la figura de la vendicatio filii, con la cual quien deseaba adoptar podía reivindicar su patria potestad ${ }^{5}$. Este también era un procedimiento in iure cessio, es decir, un modo para transferir la propiedad de cosas mancipables y no mancipables, que permitió, más adelante, la posibilidad de adoptar esclavos o peregrinos ("res non mancipi"). Con estos procedimientos los pater familias estériles o impotentes se procuraban una dinastía y una descendencia.

La adoptio, entonces, era uno de los derechos absolutos del pater familias y los hijos eran los objetos sin alma de este antiguo instituto que tenía principalmente una finalidad sucesoria. Fue en este mismo sentido que la adopción romana fue incorporada más tarde en el Code civil francés, adoptado por Napoleón Bonaparte en el año 1804, después de la Revolución Francesa. En otras palabras, esta figura jurídica fue considerada por mucho tiempo un mero derecho del adoptante y no del adoptado. Solo con las reformas al Código francés de i 829 a i 849 , los legisladores comenzaron a aproximarse al concepto asistencial de adopción en el interés de la persona adoptada ${ }^{6}$.

3 Declaurill, J., Roma y la organización del derecho, trad. Ramón García Rodrillo, Barcelona, I928, II 4 .

4 Ortega Carrillo de Albornoz, A., Derecho privado romano, Promotora Cultural Malagueña, I999, I69-I 7 I.

5 Galindo Garfias, I., La filiación adoptiva, en Biblioteca Jurídica virtual del Instituto de Investigaciones Jurídicas de la Unam, en: www.juridica.unam.mx

6 Rouast, A., "Evolución moderna de la adopción en Francia", trad. Niceto Alcalá-Zamora y Castillo, Revista de la Facultad de Derecha de México, t. I I I, n. ${ }^{\circ}$ Io, abril-junio, 1953. 
No obstante, aún el Código Civil francés de i884 en su artículo i 8 I y la Ley de Relaciones Familiares no reconocían más parentesco que el derivado de la consanguinidad y aquel por afinidad (art. 32)7. Por medio de este instituto jurídico se generaban específicos deberes para el adoptante: en primer lugar el cuidado, la educación, el sostenimiento, y en consecuencia, la representación legal y la administración de los bienes del adoptado ${ }^{8}$. Adicionalmente, existían dos diferentes tipos de adopción: aquella de menores, disciplinada por el artículo 390 c.c. francés, y la de los mayores de edad que sufren incapacidad. Esta perspectiva del Código francés representa un cambio radical en relación con la naturaleza de este instituto jurídico, por cuanto controvierte el concepto mismo de adopción, acogiendo la concepción del derecho moderno, que no la entiende sólo ni ante todo como un derecho individual del adoptante o del pater familias sobre el adoptado ("res mancipi"), sino, por el contrario, como medida dirigida en primer término a proteger y tutelar la persona del adoptado y sus derechos fundamentales.

Este aporte, totalmente innovador para la época, se ha acrecentado con las reformas del Código francés, que sirvió de modelo para muchas legislaciones en el resto del mundo, sobre todo por la aplicación de esta medida de protección en situaciones dramáticas para los menores de edad, como el abandono por parte de las familias biológicas. De hecho, con el pasar del tiempo, el aumento de la sensibilidad hacia estas problemáticas sociales -especialmente en Latinoamérica- y el incremento de la normatividad internacional para proteger a la niñez, la adopción se convirtió en una medida de restablecimiento de los derechos fundamentales de niños abandonados, definiendo así y de manera progresiva el papel que tiene este instituto jurídico en la actualidad.

\section{2. "Cada niño que no pidió venir a la vida tiene derecho a tener un hogar"9}

Actualmente, en Colombia y en muchos otros países, la adopción es, prima facie y por excelencia, una medida de protección para niños, niñas y adolescentes que fueron abandonados, y en casos más complicados maltratados o abusados por los padres naturales y/o allegados, o a los que por determinadas circunstancias

7 En México, p. ej., el Código Civil del Distrito Federal, en el artículo 292, reconoce la adopción como una fuente de parentesco civil, adicional a la consanguinidad y la afinidad, pero con los mismos efectos y obligaciones de estas. De conformidad con el código, como resultado del procedimiento de adopción, la patria potestad sobre el adoptado se radicaba en cabeza de este y dejaba subsistentes los demás derechos y obligaciones que nacen del parentesco por consanguinidad: Galindo Garfias, La filiación adoptiva, cit.

8 Arts. I67, 42 I, 422, 423, 424, 425 y 427 c.c. francés.

9 María López Escobar de Vargas, fundadora de La Casa de la Madre y el Niño, I942. 
estos no pudieron o no quisieron brindarles la protección y el respecto de sus derechos fundamentales.

En Colombia ${ }^{10}$ se define la adopción como "una medida de protección integral al niño, niña y adolescente a través de la cual, bajo la suprema vigilancia del Estado, se establece de manera irrevocable, la relación paterno filial entre personas que no la tienen por naturaleza" ${ }^{\text {I }}$.

Esta medida ofrece la posibilidad de formar un vínculo jurídico de familia cuando no haya sido posible establecer un vínculo natural con la familia de sangre. De hecho, gracias a esta figura legal, de una parte, se brinda una oportunidad de vida a niños que no pudieron contar con el amor y el cuidado de su familia biológica, y de otra, se configura una posible alternativa de formar una familia para las parejas que no pueden tener hijos. Esto último constituye solamente un efecto de carácter secundario procurado por la adopción, pues esta mantiene su naturaleza de medida de protección en nombre del interés superior del niño, no como derecho de las parejas adoptantes. Esta consideración es una clave hermenéutica muy importante para solucionar muchas controversias legales y sociales sobre el tema en la realidad jurídica de numerosos países.

En este sentido, la adopción representa la respuesta a los preceptos constitucionales e internacionales que amparan el derecho fundamental de los niños a ser amados por una familia, que es la principal responsable del respeto y de la protección de los demás derechos fundamentales de niños, niñas y adolescentes $^{\mathrm{I}}$. Así, por ejemplo, en Israel, en la Declaración de los Derechos de los Niños ( 1989 ), el principio $2 .^{\circ}$ afirma que "todo niño tiene derecho a una vida familiar, a la alimentación, a una vivienda adecuada, a protección, amor y comprensión" 33. A su vez, la Declaración de los Derechos de los Niños de Mozambique (i979) consagra que "los niños tienen derecho a crecer en un clima de paz y seguridad, rodeados de amor y comprensión” ${ }^{4}$. Por su parte, la Constitución italiana en

Instituto Colombiano del Bienestar Familiar (ICBF), Resolución 3748 de 20 Io, Lineamiento Técnico Administrativo del Programa de Adopciones.

i I Gómez Piedrahíta, H., Derecho de familia, Bogotá, Temis, I992, 288.

I2 A nivel nacional: arts. 42 a 45 Constitución Política de Colombia; arts. 7, 93 y 94 Ley 7 de 1979 (ICBF); art. 7 Ley I098 de 2006; Decreto 2737 de 1989; Ley I 564 de 20I2; entre otras. A nivel internacional: Convención Internacional sobre los Derechos de los Niños; Convención de La Haya de 1993; Carta de las Naciones Unidas; Carta Internacional de Derechos Humanos; Declaración Universal de Derechos Humanos de I948; Pacto Internacional de Derechos Económicos, Sociales y Culturales de I966; Pacto Internacional de Derechos Civiles y Políticos de I966; Protocolo Facultativo del Pacto Internacional de Derechos Civiles y Políticos; Segundo Protocolo Facultativo del Pacto Internacional de Derechos Civiles y Políticos, destinado a abolir la pena de muerte entre otros.

I3 Declaration of the Rights of the Child of Israel.

I4 Declaration of the Rights of Mozambican Children (1979). 
su artículo $3^{\left[{ }^{[5]}\right]}$ establece de manera explícita el deber de la familia de brindar amor, cuidado, educación y protección a los hijos, incluidos aquellos nacidos por fuera del matrimonio, en consideración a que ellos gozan de iguales derechos y oportunidades respecto de los hijos nacidos dentro del matrimonio. De igual manera, el derecho al amor está reconocido en la Constitución colombiana en el artículo 44: "Son derechos fundamentales de los niños: la vida, la integridad física, la salud y la seguridad social, la alimentación equilibrada, su nombre y nacionalidad, tener una familia y no ser separado de ella, el cuidado y amor, la educación y la cultura..." I6.

En Colombia, como en muchos otros países, hay numerosos niños que no son deseados por sus padres biológicos, razón por la cual pasan su infancia y adolescencia en instituciones del Estado o, en el peor de los escenarios, en la calle, sin ningún tipo de protección y bajo el constante riesgo de ser víctimas de explotación laboral y sexual o de ser reclutados por grupos armados ilegales. Por otro lado, hay muchos niños cuyos derechos fundamentales han sido quebrantados por sus mismas familias, por cuenta de maltratos y abusos: todos ellos igualmente, si es que no a fortiori, necesitan el restablecimiento de dichos derechos.

Es en este escenario que la adopción desarrolla su papel de medida de protección, con la cual el Estado brinda a todo niño que no pidió venir a la vida y que no fue deseado la posibilidad de tener un hogar. De hecho la palabra "adoptar" procede del latín "adoptare", de "ad" y "optare", es decir "desear a", y etimológicamente implica un deseo, el deseo de tener un hijo, de ser padre o madre, el cual se manifiesta por medio de "la adopción de un menor, que sin ser hijo biológico, se hace propio por el amor de una entrega generosa y total" 17 .

\section{El proceso de adopción en Colombia}

En Colombia, mediante la Ley r 2 de r99 I se aprobó la Convención sobre los Derechos del Niño adoptada por la Asamblea General de las Naciones Unidas el 20 de noviembre de i989. No obstante, antes ya existía un marco normativo. Así, por ejemplo, con la Ley 7 de i979 se entienden los términos “niño, joven” como "los menores de i 8 años". Por medio de esta ley se crea el Sistema Nacional de Bienestar Familiar como servicio público a cargo del Estado para la protección de la niñez y la familia:

I 5 Costituzione Italiana, art. 30: " $\dot{E}$ dovere e diritto dei genitori mantenere, istruire ed educare $i$ figli, anche se nati fuori dal matrimonio. I Nei casi di incapacità dei genitori, la legge provvede a che siano assolti i loro compiti. I La legge assicura ai figli nati fuori del matrimonio ogni tutela giuridica e sociale, compatibile con i diritti dei membri della famiglia legittima. / La legge detta le norme e i limiti per la ricerca della paternità".

I6 Corte Constitucional, Sentencia T-I 29 de 20 I 5.

I 7 García Sarmiento, E., Derecho de menores (Aspectos civiles, comerciales, laborales, internacionales y organismos de protección), Bogotá, Ediciones Rosaristas, I 995, 284. 
... el Instituto Colombiano de Bienestar Familiar tendrá por objeto fortalecer la familia y proteger al menor de edad. Para restablecer el derecho humano a tener una familia y no ser separado de ella, que es de orden constitucional, [... se crean] los comités de adopción del IсвF y de las instituciones autorizadas integrados por profesionales especializados como trabajadores sociales, psicólogos, el representante regional del ІсвF, el director o el representante legal de las instituciones privadas para desarrollar el programa de adopción (art. 20 Ley 7 de I979) $^{\mathrm{I} 8}$.

De otra parte, en el Decreto 2737 de 1989 o Código del Menor se definen los derechos fundamentales de los niños, niñas y jóvenes, se determinan las llamadas situaciones irregulares y los principios que rigen las normas para la protección de sus derechos, protección que puede ser de dos clases: preventiva o especial. La protección preventiva (art. 55) es el conjunto de acciones necesarias para evitar el abandono del menor y la desintegración de la familia; mientras que la especial es sucesiva a la vulneración de dichos derechos y se concreta en medidas de restablecimiento de estos.

De manera precisa, el concepto de adopción se encuentra en el artículo 6I de la Ley ro98 de 2006, por la cual se expide el Código de la Infancia y la Adolescencia, y es definido como "un mecanismo que intenta materializar el derecho del menor a tener una familia y, por ello, toda la institución está estructurada en torno al interés superior del niño, cuyos derechos prevalecen sobre aquellos de los demás".

Los actores oficiales que intervienen en el proceso de adopción en su fase administrativa y judicial son: el Ісвғ como autoridad central; el defensor de familia, que decide sobre la adoptabilidad del menor cuando esta es la última medida posible para proteger sus derechos; el juez de familia, que decreta la adopción mediante una sentencia; y, el procurador delegado para la familia, que garantiza la primacía del interés superior del menor ${ }^{19}$.

\section{¿Cuándo un niño, niña o adolescente es declarado en situación de adoptabilidad?}

En Colombia existen esencialmente tres posibilidades:

En primer lugar, con la providencia del defensor de familia que declara la adoptabilidad del niño de frente a la imposibilidad de reintegrarlo con la familia

i 8 Olaya Rodríguez, A. M. a , Breves reflexiones sobre las transformaciones del derecho de infancia y adolescencia en Colombia y la intervención disciplinaria, documento facilitado por la autora, quien es docente de la Universidad Externado de Colombia, Bogotá.

i9 Velásquez de Bernal, O. M. a, "Las paradojas de la adopción en Colombia”, El Tiempo, i4 de junio de 20 I6, disponible en: http://www.eltiempo.com/politica/justicia/problemas-de-adopcion-de-ninos-en-colombia/ı662041 6 
biológica porque persisten las circunstancias de desprotección, esto luego del proceso administrativo de restablecimiento de derechos fundamentales ${ }^{20}$ des$\operatorname{amparados}^{2 \mathrm{I}} \mathrm{y}$ vulnerados por el entorno familiar del niño, niña o adolescente.

En segundo lugar, con la autorización que el defensor de familia expide para la adopción en caso de abandono del menor o de situación irreversible de vulneración de sus derechos

Por último, con la firmeza del consentimiento otorgado por los padres biológicos para la adopción del niño, niña o adolescente, una vez oficializadas en un acta las graves razones que los llevaron a decidir de entregar el menor de edad ${ }^{22}$.

En todo caso, los niños que hayan sido abandonados, o cuyos derechos hayan sido vulnerados por sus padres biológicos, quedan bajo la protección del ICBF, en espera de la decisión del Defensor de Familia: reintegro con la familia de origen o adopción (nacional o internacional). Dicha espera según los lineamientos técnicos del IсвF no puede superar los 4 meses; sin embargo, lastimosamente en la práctica se puede demorar mucho más, incluso años. En la mayoría de los casos el ICBF busca el reintegro del menor en la familia de origen hasta el sexto grado de consanguinidad: "En cumplimiento de la Sentencia de tutela T-844 de 20 I I de la Corte Constitucional, el Instituto Colombiano de Bienestar Familiar - ICBF diseñó un protocolo que obliga a los funcionarios de la entidad a buscar, en todos los casos, a la familia extensa - basta el sexto grado de consanguinidad - de los niños, niñas y adolescentes que el ICBF ha proyectado entregar en adopción" 23 . En razón de esta demora del Estado en definir las situaciones jurídicas de estos menores de edad, muchos de ellos viven su infancia -y en el peor de los casos también su adolescencia-, en hogares proveídos por el mismo Bienestar Familiar: instituciones, fundaciones u hogares sustitutos.

Una vez emitida la declaración de adoptabilidad, el niño, niña o adolescente debe ser preparado por un equipo de profesionales (psicólogos, trabajadores sociales...) para ingresar a su nuevo entorno familiar y su nueva vida. El ICBF selecciona a las familias que garanticen un hogar estable y seguro para el desarrollo armónico del niño, luego de lo cual, también la familia comienza un proceso de preparación burocrático-administrativo y psicológico, para encontrar su(s) hijo(s) y recibirlo(s) en el seno del hogar. Hay familias que esperan por muchos años este momento, tan emocionante para ellos. Actualmente se les da trámite preferente e inmediato para su asignación familiar a aquellas solicitudes para

20 Se entiende por restablecimiento de los derechos de los niños, las niñas y los adolescentes, la restauración de su dignidad e integridad como sujetos de derechos y de la capacidad para hacer un ejercicio efectivo de los derechos que les han sido vulnerados (art. 50 C. de la Infancia y la Adolescencia).

2 I En materia de desamparo, es decir situaciones de abandono y/o que ponen en riesgo la vida, la salud o la integridad física; o la inducción a la mendicidad, la delincuencia y la prostitución de los menores de edad.

22 ICBF, Lineamiento Técnico, cit.

23 Corte Constitucional, Sentencia T-844 de 20 I I. 
niños de cualquier edad con discapacidades físicas, mentales o sensoriales, para los grupos de hermanos, y para los niños mayores de io años ${ }^{24}$.

Hoy por hoy, existen muchísimas familias en lista de espera de adopción así como un sinnúmero de niños en búsqueda de un hogar permanente: según las cifras del ICBF son 274 las familias colombianas y r.882 las extranjeras, por un total de 2. 56 familias ${ }^{25}$. En su totalidad, el Estado Colombiano cobija a Io6. I 22 entre niños, niñas y adolescentes en proceso de restablecimiento de derechos. Por otro lado, más de 5.000 niños con "características especiales" ${ }^{26}$ están bajo protección del Instituto Colombiano de Bienestar Familiar y no han encontrado una familia adoptiva.

\section{Otros protagonistas de la adopción}

Habia una vez dos mujeres que nunca se conocieron;

De una no te acuerdas, la otra la llamas mamá.

La primera te dio la vida, la segunda te enseñó a vivirla.

La primera te dio a luz y te donó el deseo de amor,

la segunda estaba allí para satisfacerlo.

Una te dio la nacionalidad, la otra el nombre.

Una la semilla de la crianza, la otra un objetivo.

Una te dio emociones, la otra llenó tus miedos.

Una miró tu primera sonrisa, la otra secó tus lágrimas.

Una te dio libremente, era todo lo que podía hacer.

La otra rezaba por un niño y Dios la ha llevado a ti.

$Y$ ahora me haces la eterna pregunta: herencia o ambiente, ¿por quién fui plasmado?

Por ninguno de los dos, solo por dos amores diferentes.

Anónimo.

24 ICBF, Lineamento Técnico, cit. El Lineamiento Técnico se constituye en una herramienta a través de la cual el IсвF tiene la posibilidad de seleccionar las familias que garanticen un hogar estable y seguro para el desarrollo armónico del niño. Si la solicitud es para niños con características y necesidades especiales, esta tendrá prelación. Una vez recibida, y confirmada la idoneidad, el proceso tomará tres meses hasta la asignación. Ante este tipo de solicitud se considerará la regla básica de que el adoptante deberá tener más de 25 años, debiendo haber I 5 años de diferencia entre adoptante y adoptado. En tal caso, la solicitud no se someterá a los turnos de las listas de adoptantes.

25 Datos actualizados a marzo de 20I6: http:/www.icbf.gov.co/portal/page/portal/PortalicBF/ Especiales/prueba/Bienestar/ProgramaAdopciones/Estadisticas\% 20P.\% 2OADoPciIones\% 20 AL\% 203 I-O3-20I6.pdf

26 El Lineamiento Técnico del ICBF (2016) considera "necesidades especiales":

- Tres (3) o más hermanos.

- Dos (2) hermanos, uno de ellos con más de ro años.

- Un/a (I) niño/a mayor de ro años sin discapacidad ni enfermedad.

- Un/a (I) niño/a con discapacidad física o mental de cualquier edad.

- Un/a (I) niño/a con enfermedad permanente (VIH, cardiológicas, renales, entre otras). 
El proceso de adopción no involucra solamente a los niños; aunque sea una medida de protección para ellos, este instituto involucra de manera evidente dos familias, la biológica y la adoptiva. "Entregar un hijo en adopción fue la decisión más dolorosa de mi vida", estas son la palabras de todas las madres gestantes de la Casa de la Madre y el $\mathrm{Niño}^{27}$ que, como muchas otras mujeres con embarazos en conflicto, eligieron no abortar y dar a luz a sus propios hijos para brindarles una nueva oportunidad de vida. Los padres biológicos viven una amplia variedad de sentimientos y experiencias relacionadas con este proceso tan dramático para ellos, incluyendo el dolor, pensamientos sobre el niño, sentimientos de culpa y vergüenza, asuntos de identidad y los efectos sobre las demás relaciones en su vida $^{28}$. Aquellos que deciden acudir a la adopción asumen una gran pérdida en sus vidas con la esperanza de que la adopción se traduzca en una mejor vida para el bebé y para ellos mismos. "El nacimiento del bebé y el hecho de entregar al bebé en adopción pueden provocar que los padres biológicos experimenten varias fases de un proceso de duelo, incluyendo fases de conmoción y de negación, tristeza y depresión, enojo, remordimiento y aceptación”29. Una vez firmado el consentimiento o una vez que el Defensor de Familia declara al niño en situación de adoptabilidad, los padres biológicos pierden totalmente la patria potestad, el derecho de parentesco civil y el derecho a saber de la vida del niño, niña o adolescente. Una vez termina el proceso, la adopción es irrevocable: el hijo adoptivo llevará los apellidos de los padres adoptantes y dejará de pertenecer a su familia biológica, extinguiéndose todo parentesco de consanguinidad ${ }^{30}$.

Por otro lado, cabe destacar la posición también difícil de la familia adoptiva, colombiana o extranjera, que por cualquier razón decide adoptar a sus hijos: hay casos de padres que no pueden tener hijos naturalmente, y hay otras situaciones en que las familias, pese a haber concebido hijos naturales, deciden brindar amor y cuidado a un niño que no tiene la fortuna de contar con un hogar. Toda familia que quiere adoptar un niño, un grupo de hermanos o un adolescente tiene que cumplir con todos los requisitos legales establecidos por el ICBF, siguiendo las

27 La fundación Casa de la Madre y el Niño es un hogar para niños en restablecimiento de derechos, niños en espera de una familia adoptiva y mujeres con embarazo no deseado, fundada por María López Escobar de Vargas en I942.

28 Child Welfare Information Gateway, Washington, D.C., U.S., Department of Health and Human Services, Children's Bureau, El impacto de la adopción en los padres biológicos, disponible en: https://www.childwelfare.gov/spanish Noviembre de 20 I 3 .

29 Romanchiк, B., Birthparent grief, Royal Oak, MI, R-Squared Press, i 999, i6.

30 ICBF, Lineamiento Técnico:

"La adopción es irrevocable.

"El adoptivo llevará los apellidos de los adoptantes.

"Por la adopción el adoptivo deja de pertenecer a su familia biológica y se extingue todo parentesco de consanguinidad.

"Los trámites que se adelanten en el IсвF en relación con las adopciones son totalmente gratuitos". 
directivas de la Convención de La Haya en Materia de Adopción ${ }^{3 \mathrm{I}}$. Según el Lineamiento Técnico Administrativo del Proceso de Adopción, del IcBF, los padres adoptivos, colombianos o extranjeros, pueden escoger si presentar su solicitud de adopción directamente al гсвғ o ante una de las instituciones acreditadas por el ICBF para la adopción (IAPAS): la única diferencia entre hacerlo ante el ICBF y ante las IAPAs radica en los costos administrativos; pero en ambos casos el proceso en su fase administrativa y judicial sigue el mismo iter ${ }^{22}$.

Entre los requerimientos legales ${ }^{33}$ se contempla que estas familias tienen que ser examinadas por psicólogos y trabajadores sociales para ser declaradas física, moral, social y psicológicamente idóneas para acoger al niño en su hogar. Además de un estudio socio-familiar, los padres adoptivos deben anexar otros documentos relacionados con su historia de vida, su trabajo, su disponibilidad, su personalidad, y si son extranjeros deben obtener los permisos necesarios para viajar y ser aceptados en Colombia, cumpliendo con los requisitos de legalización/apostilla y traducción oficial de todos los documentos requeridos. En relación con la idoneidad moral, la Corte Constitucional, en la sentencia C-8 I4 de $200 \mathrm{I}$, se ocupa de una cuestión muy importante y discutida que se relaciona con el hecho de que en el artículo 89 del Decreto 2737 de r 989 se exige, como requisito para conceder a un menor en adopción, que los aspirantes a padres adoptantes demuestren idoneidad "moral suficiente". En dicho fallo se sostiene:

... en ejercicio del derecho a la adopción, la condición moral de una persona no puede ser un criterio válido de restricción, como no lo es tampoco para contraer matrimonio, formar una familia o procrear un hijo. Además, no hay razón plausible que obligue a quien tramita una solicitud de adopción, a optar o inclinarse por una moral especial, pero mucho menos por la del funcionario encargado de tramitar la adopción [...] [I]mpedirle a una persona por razón de su conducta moral que adelante un proceso de adopción, es formular un reproche en contra de su opción de vida, lo cual resulta discriminatorio frente a los padres biológicos, a quienes jamás se les impone ningún requisito moral para procrear.

3 I Ibíd.

32 La adopción tiene dos etapas: Etapa I - Administrativa, que se surte ante el ICBF, en la cual se declara adoptable al niño; Etapa 2 - Judicial: la adopción es decretada mediante sentencia judicial en los juzgados de familia, cuya sentencia debidamente ejecutoriada establece la relación paterno-filial.

33 El artículo 68 del Código de la Infancia y la Adolescencia establece que para adoptar de manera conjunta o individual se debe:

- Ser plenamente capaz.

- Tener 25 años de edad cumplidos.

- Demostrar la idoneidad física, mental, moral y social suficiente para ofrecerle una familia adecuada y estable a un menor de i 8 años de edad.

- Tener al menos i 5 años más que el adoptable. 
En la práctica, un padre adoptivo, colombiano o extranjero, que adelanta una solicitud de adopción ante el ICBF o las IAPAs puede esperar mucho tiempo, hasta años para ser declarado idóneo, y el resultado es que, tristemente, muchas familias adoptivas terminan por desistir.

\section{La adopción internacional en Colombia}

El "Convenio relativo a la protección del niño y a la cooperación en materia de adopción internacional", suscrito en La Haya el 29 de mayo de 1993 y aprobado en Colombia por medio de la Ley 265 del 25 de enero de I996, se inspira expresamente en el principio del interés superior del menor. El artículo primero de dicho Convenio señala como su objetivo "[e]stablecer garantías para que las adopciones internacionales tengan lugar en consideración al interés superior del niño y al respecto a los derechos fundamentales que le reconoce el Derecho Internacional".

Según el Convenio, una familia que quiera adoptar internacionalmente deberá acudir ante la autoridad central de su país. De acuerdo con el Lineamiento Técnico del IсBF que incorporan la normatividad internacional del Convenio, la familia extranjera debe dirigirse a los organismos acreditados por el IсBF (autoridad central en Colombia en materia de adopción) que se ocupan del proceso de adopción en el extranjero. En cada organismo hay un coordinador del programa que orientará a la familia en todos los pasos a seguir; aclarando que los futuros padres adoptantes, antes de demostrar su idoneidad para adoptar en el país receptor, tienen que ser aprobados por el organismo de su país.

Si son aprobados, el organismo envía a Colombia el expediente de la familia con todos los documentos requeridos, y el representante legal del organismo extranjero en Colombia los radica ante el ICBF, que deberá declarar la idoneidad (o no idoneidad) de la familia extranjera. En el caso de niños con necesidades especiales para los cuales no hay familia en Colombia, es decir que ya pasaron a comité de adopción varias veces sin ser asignados, el procedimiento es más rápido en nombre del interés superior del niño, niña o adolescente.

Cabe anotar que, en junio del 2013, el ICBF suspendió la recepción de solicitudes de familias extranjeras residentes en el exterior para adoptar niños sanos de $\mathrm{O}$ a 6 años. Se esperaba que las solicitudes que estaban en lista de espera en ese momento se tramitaran con relativa celeridad. Sin embargo, este no ha sido el caso. Actualmente el ICBF, con los Organismos internacionales que colaboran con el programa de adopción, está promoviendo la adopción de niños con características y necesidades especiales ( 3 o más hermanos; 2 hermanos, uno mayor de Io años; tener Io años o más; tener discapacidad física o mental; tener enfermedad que demande atención especializada). Quienes generalmente los adoptan son 
familias extranjeras. Si no fuera por ellas, muchos menores se quedarían sin ho$\operatorname{gar}^{34}$.

Después de la aprobación del nuevo Lineamiento Técnico, en marzo de 2016 el IсвF modificó el concepto de niños con necesidades especiales, subiendo la edad de 7 a ro años. Esto significa que actualmente las familias extrajeras no pueden adoptar niños sanos menores de ro años, a menos que pertenezcan a un grupo de 3 o más hermanos. Para cada niño declarado en adoptabilidad se examina siempre primero la posibilidad de una adopción nacional en cualquiera de los casos (Convenio de La Haya de r993). Sin embargo, lastimosamente no siempre la adopción nacional se revela como la mejor solución para todo niño, especialmente para niños grandes que desean borrar su difícil pasado y empezar de nuevo desde cero: "Yo no tengo una familia biológica, yo nací en el momento en el cual mamá y papá me adoptaron, ellos son mi única familia” (Arianna, 24 años, adoptada en Italia cuando era bebé); "Yo no quiero a mis padres, quiero una familia nueva y una vida diferente, ojalá sean [sic] en otro país" (Kevin, I 4 años, adoptado en Estados Unidos).

\section{El cierre de un ciclo: derechos de los niños adoptados a conocer sus orígenes}

Generalmente se considera terminado el proceso de adopción con el encuentro del niño, niña o adolescente con su familia adoptiva, la integración entre ellos y la sucesiva sentencia judicial que declara la adopción plena. No obstante, esto no es del todo cierto: la adopción es una decisión vital y un proceso que proyecta sus efectos durante toda la vida. El vínculo de filiación que se crea es irrevocable y permanente, y la ley debe tutelar esta nueva familia también después del momento de su formación. De hecho, sea que se trate de adopción nacional o de adopción internacional, el seguimiento post adopción es fundamental para que tenga éxito y para asegurar la buena adaptación del niño a su nuevo entorno familiar y social 35 . Las familias adoptivas deben informar al ICBF sobre las condiciones en las cuales se encuentra el niño por medio de informes específicos ${ }^{36}$. La periodicidad de esos informes y la duración del período de seguimiento varían según el Estado de origen; para el caso de Colombia,

34 Velásquez de Bernal, cit.

35 Centro Internacional de Referencia para los Derechos del Niño Privado de Familia (ssi/cIR), página web: http://www.iss-ssi.org

36 Suelen ser trabajadores sociales de organismos acreditados, privados o del Gobierno del Estado de acogida quienes se entrevistan con la familia adoptiva y redactan los informes con fotografías que el organismo autorizado (o la autoridad central o competente) envía después al Estado de origen. En algunos casos son los propios padres adoptivos quienes redactan los informes. 
... se realizarán cuatro informes, durante los dos años siguientes a la declaración de ejecutoria de la sentencia de adopción y el primero de ellos se realizará a los tres meses y los otros tres informes cada seis meses. Deberán enviarse a la regional o institución autorizada en la cual se hizo la asignación debidamente apostillados, traducidos por traductor oficialmente autorizado y con registro fotográfico; copia de los mismos se remitirá a la Subdirección de Adopciones. Los informes de seguimiento serán estudiados y remitidos por parte de la Subdirección de Adopciones a la regional de origen del niño, niña o adolescente, cuando estos denuncien antecedentes del vulneración de los derechos en el servicio de protección 37 .

Sin embargo, este seguimiento presenta algunos elementos adicionales. Los servicios post adopción proporcionados por los Estados deben ser aptos para responder a las necesidades particulares de las familias adoptivas, nacionales e internacionales, y garantizar que los derechos e intereses de los niños que buscan sus orígenes sean preservados ${ }^{3}$. El derecho del adoptado que quiera conocer su familia de origen está expresado en el artículo 76 de la Ley ro98 de 2006: "todo adoptado tiene derecho a conocer su origen y el carácter de su vínculo biológico. Los padres adoptivos juzgarán el momento y las condiciones en que no resulte desfavorable para el niño, niña o adolescente conocer dicha información”. De hecho, los niños tienen derecho a conocer su historia y sus padres adoptantes estimarán el momento oportuno de compartir la información, teniendo en cuenta las condiciones específicas de su desarrollo y su edad. En algunos casos los padres biológicos dejan una carta al niño explicándole las razones que dieron lugar a su entrega, anexando su historia en la documentación. En Colombia la persona adoptada que llega a la mayoría de edad tiene derecho a tener y conocer la información disponible sobre sus antecedentes familiares y las circunstancias que rodearon la adopción. Igualmente, en España, desde que se aprobó la Ley de Adopción Internacional el 28 de diciembre de 2007, todos los hijos, incluso los concebidos mediante técnicas de reproducción asistida, tienen derecho a conocer sus orígenes biológicos a partir de la mayoría de edad. Por otro lado, en Italia la ley determina que hay que esperar hasta los 25 años de edad, proceso que resulta más complicado para los niños adoptados, sobre todo cuando los padres biológicos deciden mantenerse en el anonimato.

En Colombia el sujeto interesado deberá presentar una solicitud por escrito a la Subdirección de Adopciones del гсвF, la cual le informará sobre el procedimiento a seguir ${ }^{39}$. Para muchos hijos adoptados, su historia y origen familiar

37 ICBF, Lineamiento Técnico, cit., 38.

$3^{8}$ Centro Internacional de Referencia para los Derechos del Niño Privado de Familia (ssi/cir), http://www.iss-ssi.org

39 ICBf, Lineamiento Técnico, cit. 
son como una hoja en blanco pendiente de ser escrita. El temor de las familias a revelar la verdad sobre sus orígenes conduce a muchos de ellos a inhibir su capacidad de preguntar y a frenar de manera inconsciente su curiosidad natural: "Una de las consecuencias de la ausencia de información es anular el deseo de conocer. Estas situaciones conducen a los hijos a pensar que saber, puede poner en peligro el amor que tienen los hijos por sus padres"40. Según algunas investigaciones realizadas por psicoanalistas, "el hijo adoptivo, por no saber de sus orígenes, se vuelve un ser alienado de sí mismo". Cada niño adoptado, en su corazón quisiera saber de sus padres biológicos y conocer las razones por las cuales lo entregaron en adopción. Esta curiosidad no implica necesariamente que el niño esté rechazando a la familia adoptiva, por el contrario, constituye una inquietud inherente al mismo ser humano. De hecho, la búsqueda de los orígenes es un tema arquetípico, un motivo mítico presente en todos nosotros. El ser humano desde siempre se pregunta: ¿de dónde vengo?, ¿dónde nací?, ¿por qué existo?, ¿cuáles son las raíces de todas las cosas? En la mitología griega existía el mito de Dionisio, quien representa el niño divino que, en todos nosotros, vive esta eterna búsqueda. Hillman afirma al respecto:

Esta es la figura clásica del Puer Aeternus, el componente eternamente joven de cada psique humana $[\ldots]$ que está siempre ansiando, y que al final busca a la madre arquetípica. Nuestro pothos se refiere a nuestra naturaleza angelical, y nuestras ansias y viajes errantes por el mar son efectos, en nuestras vidas personales, de las imágenes transpersonales que nos solicitan, nos impelen y nos fuerzan a imitar los destinos míticos. En este sentido podemos decir que somos todos adoptados y que en cada uno de nosotros habita un adoptado, cuyas carencias y temores remiten a un Dios-Padre para consuelo, pero clama por la venganza del abandono, del sentimiento de debilidad ${ }^{4}$.

Por lo tanto, dicho conflicto es constitutivo de todo ser humano. En el mito griego, Dionisio baja hasta el fondo del Hades para buscar a su madre Sémele y conferirle la inmortalidad: "Hades puede simbolizar el inconsciente colectivo en sus profundidades [...] El niño adoptivo, como cualquier otro niño, en algún momento de su vida, naturalmente, indaga sobre de dónde vino, para poder orientarse para dónde va"42.

La integración de lo que el niño adoptivo trae de sus orígenes y de su pasado resulta fundamental para formarse como persona y, a veces, para conformar su propia familia. Por estas razones para muchas personas adoptadas esta etapa es

4I Hillman, J., Estudios de psicología arquetípica, Rio de Janeiro, Achiamé, I 98 I, 67 y 77.

42 MaAme Zimeo, A., La adopción y el inconsciente: un abordaje simbólico de la psicología analítica, disponible en: http://www.fundacion-jung.com.ar/cuadernos/adopcion.htm 
esencial para concluir verdaderamente el proceso de adopción desde el punto de vista de su destinatario principal. El "niño" en este proceso sigue siendo considerado "niño" legal y psicológicamente, aunque sea mayor de edad: de hecho, es el único sujeto que tiene derecho de buscar a su familia biológica, y no al contrario.

"La restitución de lo que el niño vivió permitirá el sentimiento de su continuidad y de su identidad. Se trata de un proceso que reconstruye el pasado en función del presente, con la mirada hacia el futuro" 43 . El niño adoptado que quiera conocer sus orígenes podrá entonces cumplir su destino: el "quién soy" y el "para qué soy" 44, y de esta manera cerrar el círculo y llegar al verdadero cumplimiento de su proceso de adopción.

\section{Conclusiones}

El proceso de adopción en todas sus proyecciones legales, psicológicas y emocionales corresponde a un cuadro muy complejo y lleno de colores. Lastimosamente muchas personas tienen una serie de prejuicios sobre la familia biológica y/o las familias adoptivas por desconocimiento. En Colombia muchas personas consideran la adopción como una suerte de "venta" de niños y preguntan a los adoptados "por qué te regalaron" o "por qué te abandonaron”, sin ningún respeto por las implicaciones psicológicas, emocionales y legales antes mencionadas.

Por el contrario, el acto de amor infinito que encarna la adopción tiene mucho que enseñar acerca del concepto de "familia" y de "amor", considerando: los sentimientos encontrados de la familia biológica en su difícil decisión, pero a la vez dolorosa y admirable; la condición maravillosa del niño adoptado que tuvo la fortuna de recibir otra oportunidad de vida, y, en fin, la posición de la familia adoptiva que ama sin condiciones a otro ser humano sin necesidad de lazos de sangre. Solo la cultura, de la mano de la ley, puede proteger y mejorar el proceso de adopción en nombre del interés superior de los 5000 niños, niñas y adolescentes que hoy en día están creciendo en instituciones en Colombia. Cada uno de ellos merece sonreír con una familia para toda la vida.

\section{Bibliografía}

Abalo Gandía, M. ${ }^{\mathrm{a}}$, Todos los niños adoptados tienen derecho a conocer su origen e historia, disponible en: http://www.elbebe.com/adopcion/reportaje-sobreadopcion-todos-hijos-adoptados-tienen-derecho-conocer-su-historia-yorigen-pag-I-3

Brandão, J. S., Mitologia griega, vol. i, Vozes, Petrópolis, I 996.

43 Ibíd.

44 Ibíd. 
De Saint-Exupéry, A., El Principito, Reynal \& Hitchcock (euA), I 943.

Declarruil, J., Roma y la organización del derecho, trad. Ramón García Rodrillo, Barcelona, I928.

Galindo Garfias, I., La filiación adoptiva, en Biblioteca Jurídica virtual del Instituto de Investigaciones Jurídicas de la Unam.

García Sarmiento, E., Derecho de menores (Aspectos civiles, comerciales, laborales, internacionales y organismos de protección), Bogotá, Ediciones Rosaristas, I 995.

Gómez Piedrahíta, H., Derecho de familia, Bogotá, Temis, I992.

Hillman, J., Estudios de psicologia arquetípica, Rio de Janeiro, Achiamé, I98I.

López Escobar de Vargas, M., Fundadora de La Casa de la Madre y el Nino, Libro de los 70 años, 2013 .

Maame Zimeo, A., "La adopción y el inconsciente: un abordaje simbólico de la psicología analítica”, disponible en: http://www.fundacion-jung.com.ar/ cuadernos/adopcion.htm

Mazeaud, H. y L., Lecciones de derecho civil, Parte r. ${ }^{\text {a, }}$, vol. III, Buenos Aires, Ediciones Jurídicas Europa-América, I976.

Ortega Carrillo de Albornoz, A., Derecho privado romano, Promotora Cultural Malagueña, I999.

Parrondo, L. y Casalilla, J. A. (coords.), J. J. García Ferrer (dir.), El reto de ser padres, Barcelona, Salvat, 2008.

Rouast, A., "Evolución moderna de la adopción en Francia”, trad. Niceto Alcalá-Zamora y Castillo, Revista de la Facultad de Derecho de México, t. I i I , n. ${ }^{\circ}$ Io, abril-junio, I953.

Rodríguez Olaya, A. Ma., Breves reflexiones sobre las transformaciones del derecho de infancia y adolescencia en Colombia y la intervención disciplinaria, documento facilitado por la autora, docente Universidad Externado de Colombia, Bogotá.

Rodríguez Cuarta, P., “La eterna espera de los niños huérfanos”, El Espectador, I 7 de febrero de 2015 . 
Velásquez de Bernal, O. M. a "Las paradojas de la adopción en Colombia”, El Tiempo, I4 de junio de 2016.

\section{Fuentes legales y jurisprudenciales}

Carta de las Naciones Unidas (I945).

Código Civil Francés (I 804, I 829, I 849 y I 884).

Constitución italiana (I948).

Constitución Política de Colombia (I991).

Convención de La Haya (1954).

Convención Internacional sobre los Derechos de los Niños (I989).

Convenio de La Haya sobre Adopciones Internacionales (I993).

Corte Constitucional de Colombia, Sentencias T-r 29 de 20 I 5, T-844 de 20 I I y T-5O2 de 201 I.

Declaración de los Derechos de los Niños de Israel (I989).

Declaración de los Derechos de los Niños de Monzambique (I979).

Declaración Universal de Derechos Humanos (I948).

Decreto 2737 de I989.

ICBF, Resolución 255 I de marzo de 20I6, Reforma al Lineamiento Técnico para Adoptar.

ICBF, Resolución 3748 de 20 Io, Lineamiento Técnico para Adoptar.

Ley 1098 de 2006.

Ley 564 de 2012.

Ley 7 de I979.

Pacto Internacional de Derechos Civiles y Políticos ( I966). 
Pacto Internacional de Derechos Económicos, Sociales y Culturales (I966).

Protocolo Facultativo del Pacto Internacional de Derechos Civiles y Políticos (1976).

\section{Plataformas web}

http://www.oas.org

http://www.icbf.gov

http://www.childwelfare.gov

http://www.lavanguardia.com

http://www.iss-ssi.org

http://www.eltiempo.com 